\title{
Application of propofol combined with sevoflurane anesthesia in staged hepatectomy liver detachment and portal vein ligation
}

\author{
FEI XU ${ }^{1}$, HONGBO JIANG ${ }^{2}$, MEISHAN JIN $^{3}$ and QIHUA PENG ${ }^{4}$ \\ ${ }^{1}$ Department of Anesthesiology, Jilin Hepatobiliary Hospital, Changchun, Jilin 130062; ${ }^{2}$ Changchun Children's Hospital, \\ Changchun, Jilin 132001; ${ }^{3}$ Department of BMS, Aviation University of Air Force, Changchun, Jilin 130022; ${ }^{4}$ Department \\ of Ultrasonography, Changchun Obstetrics and Gynecology Hospital, Changchun, Jilin 130011, P.R. China
}

Received December 13, 2018; Accepted July 7, 2019

DOI: $10.3892 /$ etm.2021.10353

\begin{abstract}
The aim of the present study was to investigate the application of propofol combined with sevoflurane anesthesia in associating liver partition and portal vein ligation for staged hepatectomy (ALPPS). A retrospective analysis of 40 patients with liver cancer who underwent ALPPS was performed. The study included 21 (control group) and 19 (observation group) patients who were administered propofol anesthesia and propofol in combination with sevoflurane anesthesia, respectively. Changes in liver function indicators, routine blood parameters and blood coagulation function, as well as cognitive function (mini-mental state examination) were recorded. The total bilirubin and direct bilirubin levels and the alanine aminotransferase (ALT) level after the first- and second-stage operation in the two groups was also higher than that prior to the first-stage operation $(\mathrm{P}<0.05)$, and the ALT level was significantly lower in the two groups after the second-stage operation compared with that prior to the second-stage operation $(\mathrm{P}<0.05)$. The AST level after the first- and second-stage operation was lower than that prior to the first- and second-stage operation, respectively $(\mathrm{P}<0.05)$. The white blood cell count after the second-stage operation was significantly lower compared with that prior to the second-stage operation $(\mathrm{P}<0.05)$. The plasma fibrinogen (FIB) level was higher after the first-stage operation compared with that prior to the first-stage operation $(\mathrm{P}<0.05)$. The prothrombin time in the two groups of patients was higher after the second-stage operation compared with that prior to the second-stage operation $(\mathrm{P}<0.05)$, whereas the FIB level was lower $(\mathrm{P}<0.05)$ and the international normalized ratio was not significantly different $(\mathrm{P}>0.05)$. The degree of cognitive
\end{abstract}

Correspondence to: Dr Qihua Peng, Department of Ultrasonography, Changchun Obstetrics and Gynecology Hospital, 615 West Fifth Road, Changchun, Jilin 130011, P.R. China E-mail: pengqhi@163.com

Key words: propofol, sevoflurane, staging hepatectomy of liver detachment and portal vein ligation, liver function, coagulation function, cognitive function decline prior to the first/second-stage operation, according to mini-mental state examination scores, was different from that after the first/second-stage operation $(\mathrm{P}<0.05)$. In conclusion, propofol combined with sevoflurane has a good application value in ALPPS.

\section{Introduction}

Liver cancer is one of the most common malignant tumor types in the world. Its incidence is high in developing countries. The associated mortality rate is second only to gastric cancer and esophageal cancer (1). The disease may occur in individuals of all ages but it most commonly occurs at an age of onset of 40-49 years (2). The cancer is more common in male than in female patients, with men accounting for approximately 6 out of 7 cases. China has a high incidence of liver cancer, with cases accounting for $42 \%$ of liver cancer cases worldwide, and its incidence exhibits annual increases. The number of newly diagnosed patients in China is $\sim 600,000$ per year with an estimated 200,000 individuals succumb to liver cancer each year $(3,4)$.

Surgical treatment has always been the major treatment method for liver cancer, but the residual liver volume after hepatectomy is insufficient to maintain normal liver function due to the late detection of liver cancer in certain patients or due to the presence of a large liver tumor. However, surgery is likely to increase complications or risk of mortality, which limits the use of hepatectomy $(5,6)$. It is generally thought that if the volume of the liver removed does not exceed $80 \%$ of the original volume, it does not affect liver regeneration, thus preventing liver failure (7). Associating liver partition and portal vein ligation for staged hepatectomy (ALPPS) is an effective method for the treatment of patients with liver cancer who cannot undergo hepatectomy and may promote short-term rapid proliferation of residual liver cells after surgery $(8,9)$. However, as ALPPS is complex and the operation time is longer than that of common hepatectomy, the anesthesia requirements for ALPPS are high, which limits the use of numerous anesthetic methods and anesthetics. For patients with ALPPS, propofol is one of the most widely used drugs with low toxicity, low liver metabolism and no accumulation $(10,11)$. Sevoflurane is a novel type of inhaled anesthetic with no upper respiratory tract irritation and low respiratory 
inhibition. It has little effect on hemodynamics, as it blocks the action of N-methyl-D aspartate receptors. After inhalation is terminated, it may be quickly metabolized and eliminated through the respiratory system (12). However, to the best of our knowledge, studies have reported on the use of sevoflurane in ALPPS have yet to be performed.

In the present study, the medical records of patients with liver cancer who were anesthetized with propofol or sevoflurane in ALPPS were retrospectively analyzed and the combined application of sevoflurane in ALPPS was evaluated.

\section{Materials and methods}

Research subjects. A retrospective analysis of 40 medical cases of liver cancer who underwent liver detachment and portal vein ligation was performed at the Jilin Hepatobiliary Hospital (Changchun, China) between November 2007 and December 2017. The mean age of the patients was $45.62 \pm 5.36$ years and the study included 21 (control group) and 19 (observation group) patients who were administered propofol anesthesia and who received propofol in compliance with sevoflurane anesthesia, respectively. On the basis of pathology, all patients were diagnosed with liver cancer, ASA grade II/III, normal white blood cell (WBC) and no distant metastasis based on imaging diagnosis, consistent with the surgical indication of ALPPS (13). The patients did not receive any anti-tumor treatment pre-operatively and there was no previous history of other tumors, no pre-operative abnormalities in the organs, including the heart and kidney, or abnormal bleeding or coagulation abnormality at the pre-operative stage. None of the patients had any allergy to propofol or sevoflurane, and there was past evidence of alcohol abuse or use of nitroglycerin. The following patients were excluded: Those who failed to undergo the second surgery, those with a survival period of $<3$ months, those who died during the study period, those with contraindications for anesthesia, those with a pre-operative mini-mental state examination (MMSE) score (14) of <24, those with incomplete patient data, those with a history of hepatitis, those with mental or learning dysfunction, and those with a tumor of large diameter $(>15 \mathrm{~cm})$. The study was approved by the hospital ethics committee of Jilin Hepatobiliary Hospital (Jilin, China) and the patient or a family member signed an informed consent form.

Anesthetic method. All patients underwent two surgical anesthesia treatments. All patients fasted $8 \mathrm{~h}$ pre-operatively and intake of medications was prohibited. An intravenous injection of $0.3 \mathrm{mg}$ scopolamine (Chengdu No. 1 Pharmaceutical Co., Ltd.) was administered $30 \mathrm{~min}$ pre-operatively. Arterial pressure, central venous pressure, electrocardiogram, blood pressure, heart rate, pulse and blood oxygen saturation were recorded. Anesthesia was induced using $0.2 \mathrm{mg} / \mathrm{kg}$ midazolam (Jiangsu Enhua Pharmaceutical Co., Ltd.), $10 \mu \mathrm{g} / \mathrm{kg}$ remifentanil (Jiangsu Enhua Pharmaceutical Co., Ltd.) and $0.2 \mathrm{mg} / \mathrm{kg}$ atracurium (Zhejiang Xianju Pharmaceutical Co., Ltd.). After induction, endotracheal intubation was performed and an anesthesia machine (Yi'an anesthesia machine Aeon7200, Shanghai Hanfei Medical Device Co., Ltd.) was used for mechanical ventilation. The tidal volume was $8-10 \mathrm{ml} / \mathrm{kg}$ and the respiratory rate was 12-14 times/min. For anesthesia maintenance, the control group was treated with propofol (Guangdong Jiabo Pharmaceutical Co., Ltd.) for target-controlled infusion (plasma concentration, $3 \mu \mathrm{g} / \mathrm{ml}$ ) and the observation group was treated with propofol and inhaled sevoflurane (0.5 MAC; Futian Gutian Pharmaceutical Co., Ltd.) for target-controlled infusion. The two groups were treated with continuous infusion of remifentanil (0.05-0.25 $\mu \mathrm{g} / \mathrm{kg} / \mathrm{min}$; Jiangsu Enhua Pharmaceutical Co., Ltd.). In the course of the surgery, $0.1 \mathrm{mg} / \mathrm{kg}$ of benzenesulfinic acid atracurium was added to maintain muscle relaxation based on the condition and the bispectral index (15), which is one of several technologies used to monitor the depth of anesthesia, was maintained between 40 and $60 \%$.

Observational indexes. For liver cancer surgery, portal vein embolization or liver disconnection and portal vein ligation was defined as the first stage, while ALPPS was the second stage. The immediate hemodynamic changes in the two groups of patients prior to and after the first-stage and second-stage operation were recorded. Changes in liver function indicators, in blood routine parameters and in blood coagulation function, as well as cognitive function (MMSE) 3 days prior to and after the first-stage operation $/ 3$ days prior to and after the second-stage operation/after the second-stage operation were recorded.

Statistical analysis. SPSS 19.0 (IBM Corp.) was used for statistical analysis. The enumeration data were expressed as $n$ $(\%)$, and the ratio was compared using the $\chi^{2}$ test. Measurement data were expressed as the mean \pm standard deviation, and an independent-samples t-test was used for comparison of between two groups, while ANOVA with Bonferroni's post-hoc test was performed for multiple-group comparisons. $\mathrm{P}<0.05$ was considered to indicate statistical significance.

\section{Results}

General patient characteristics. The control group comprised 21 patients (11 male and 10 female patients), with a mean age of $44.91 \pm 5.32$ years. The observation group was composed of 19 patients, including 10 male and 9 female patients, with a mean age of $46.33 \pm 5.64$ years. No significant difference was observed in sex and age between the two groups $(\mathrm{P}>0.05)$. The number of surgical interval days, liver volume after the first-stage operation, liver volume prior to the second-stage operation, the liver volume growth rate, operation time of the first- and second-stage operation, the extent of first- and second-stage bleeding during surgery, the degree of education and area of residence were not significantly different between the two groups (all $\mathrm{P}>0.05$; Table I).

Hemodynamic changes in the two groups of patients. The mean arterial pressure (MAP), heart rate and oxygen saturation were not significantly different between the two groups prior to and after the first-stage operation, as well as prior to and after the second-stage operation $(\mathrm{P}>0.05)$. In both groups of patients, although minor oscillations could be observed in the MAP before and after the first and second surgeries, none of the differences in this category were found to be statistically significant $(\mathrm{P}>0.05$; Table II). 
Table I. General information of the cohort.

\begin{tabular}{|c|c|c|c|c|}
\hline Item & Control group $(n=21)$ & Observation group $(n=19)$ & t-value & P-value \\
\hline Sex & & & $<0.001$ & 0.987 \\
\hline Male & $11(52.38)$ & $10(52.63)$ & & \\
\hline Female & $10(47.62)$ & $9(47.37)$ & & \\
\hline Age (years) & $44.91 \pm 5.32$ & $46.33 \pm 5.64$ & 0.822 & 0.417 \\
\hline Operative interval (days) & $20.35 \pm 2.12$ & $19.64 \pm 2.06$ & 1.072 & 0.291 \\
\hline \multicolumn{5}{|l|}{ Post-operative liver volume (1) } \\
\hline Primary surgery & $0.39 \pm 0.12$ & $0.40 \pm 0.11$ & 0.274 & 0.786 \\
\hline Secondary surgery & $0.56 \pm 0.13$ & $0.57 \pm 0.14$ & 0.234 & 0.816 \\
\hline Liver volume growth rate (\%) & $43.59 \pm 3.72$ & $42.50 \pm 3.69$ & 0.929 & 0.358 \\
\hline \multicolumn{5}{|l|}{ Operative time $(\min )$} \\
\hline Primary surgery & $231.42 \pm 11.33$ & $224.59 \pm 12.36$ & 1.824 & 0.076 \\
\hline Secondary surgery & $281.17 \pm 20.12$ & $286.75 \pm 18.49$ & 0.910 & 0.369 \\
\hline \multicolumn{5}{|l|}{ Bleeding (ml) } \\
\hline Primary surgery & $200.66 \pm 12.12$ & $208.15 \pm 13.33$ & 1.862 & 0.070 \\
\hline Secondary surgery & $2512.86 \pm 142.44$ & $2583.47 \pm 152.13$ & 1.516 & 0.138 \\
\hline Degree of education & & & 0.007 & 0.935 \\
\hline Junior high school and below & $8(38.10)$ & $7(36.84)$ & & \\
\hline Junior high school above & $13(61.90)$ & $12(63.16)$ & & \\
\hline $\mathrm{R}$ Area of residence & & & 0.382 & 0.536 \\
\hline Rural & $9(42.86)$ & $10(52.63)$ & & \\
\hline Urban & $12(57.14)$ & $9(47.37)$ & & \\
\hline
\end{tabular}

Values are expressed as the mean \pm standard deviation or $\mathrm{n}(\%)$.

Table II. Hemodynamic changes in the two groups of patients.

\begin{tabular}{lccc}
\hline Parameter & Control group $(\mathrm{n}=21)$ & Observation group $(\mathrm{n}=19)$ & $\mathrm{t}$-value \\
\hline MAP (mmHg) & & & \\
Prior to first-stage operation & $104.38 \pm 9.64$ & $102.49 \pm 9.42$ & 0.626 \\
Immediately after first-stage operation & $108.94 \pm 10.13$ & $107.42 \pm 10.09$ & 0.475 \\
Prior to second-stage operation & $110.42 \pm 9.84$ & $111.17 \pm 9.93$ & 0.637 \\
Immediately after second-stage operation & $107.25 \pm 10.32$ & $106.44 \pm 10.73$ & 0.240 \\
Heart rate (second/minute) & & & 0.301 \\
Prior to first-stage operation & $83.42 \pm 7.14$ & $84.12 \pm 7.17$ & 0.765 \\
Immediately after first-stage operation & $82.39 \pm 6.37$ & $84.02 \pm 6.74$ & 0.309 \\
Prior to second-stage operation & $83.65 \pm 6.96$ & $82.41 \pm 6.14$ & 0.759 \\
Immediately after second-stage operation & $83.47 \pm 6.48$ & $83.17 \pm 6.69$ & 0.595 \\
Blood oxygen saturation (\%) & & & 0.437 \\
Prior to first-stage operation & $96.34 \pm 4.33$ & $96.72 \pm 4.25$ & 0.556 \\
Immediately after first-stage operation & $97.58 \pm 3.26$ & $98.22 \pm 3.37$ & 0.886 \\
Prior to second-stage operation & $97.15 \pm 4.25$ & $97.42 \pm 4.17$ & 0.215 \\
Immediately after second-stage operation & $98.36 \pm 4.31$ & $98.27 \pm 4.28$ & 0.831 \\
\hline
\end{tabular}

MAP, mean arterial pressure.

Changes in liver function indicators in the two groups of patients. Total bilirubin (Tbil), direct bilirubin (Dbil), alanine aminotransferase (ALT) and aspartate aminotransferase
(AST) levels were not significantly different between the two groups prior to and after the first-stage operation, as well as prior to and after the second-stage operation $(\mathrm{P}>0.05)$. The 
Table III. Changes in liver function indicators in the two groups of patients.

\begin{tabular}{lcccr}
\hline Parameter & Control group $(\mathrm{n}=21)$ & Observation group $(\mathrm{n}=19)$ & F-value & P-value \\
\hline Tbil $(\mu$ mol/l) & & & & \\
Prior to first-stage operation & $18.21 \pm 1.12$ & $18.43 \pm 1.09$ & 0.766 & 0.312 \\
After first-stage operation & $21.25 \pm 1.22^{\mathrm{a}}$ & $21.67 \pm 1.18^{\mathrm{a}}$ & 1.953 & 0.225 \\
Prior to second-stage operation & $17.32 \pm 1.15$ & $17.84 \pm 1.14$ & 1.476 & 0.142 \\
After second-stage operation & $30.47 \pm 1.86^{\mathrm{a}}$ & $31.44 \pm 1.93^{\mathrm{a}}$ & 1.789 & 0.134 \\
Dbil $(\mu$ mol/l) & & & & \\
Prior to first-stage operation & $14.74 \pm 0.75$ & $14.36 \pm 0.76$ & 1.625 & 0.141 \\
After first-stage operation & $19.58 \pm 1.21^{\mathrm{a}}$ & $19.02 \pm 1.18^{\mathrm{a}}$ & 1.512 & 0.126 \\
Prior to second-stage operation & $13.35 \pm 1.05$ & $13.87 \pm 1.06$ & 1.469 & 0.135 \\
After second-stage operation & $20.44 \pm 1.34^{\mathrm{a}}$ & $21.81 \pm 1.42^{\mathrm{a}}$ & 1.552 & 0.162 \\
ALT $(\mathrm{U} / \mathrm{l})$ & & & & \\
Prior to first-stage operation & $211.35 \pm 22.48$ & $212.12 \pm 22.56$ & 0.110 & 0.923 \\
After first-stage operation & $325.12 \pm 26.78^{\mathrm{a}}$ & $334.56 \pm 25.79^{\mathrm{a}}$ & 1.134 & 0.285 \\
Prior to second-stage operation & $105.42 \pm 11.25$ & $109.34 \pm 11.26$ & 1.108 & 0.292 \\
After second-stage operation & $42.73 \pm 7.31^{\mathrm{a}}$ & $46.29 \pm 6.99^{\mathrm{a}}$ & 1.523 & 0.152 \\
AST (U/l) & & & & \\
Prior to first-stage operation & $345.74 \pm 28.17$ & $351.13 \pm 28.42$ & 0.611 & 0.544 \\
After first-stage operation & $252.15 \pm 24.25^{\mathrm{a}}$ & $254.33 \pm 24.72^{\mathrm{a}}$ & 0.278 & 0.713 \\
Prior to second-stage operation & $259.87 \pm 23.14$ & $262.48 \pm 23.56$ & 0.360 & 0.744 \\
After second-stage operation & $42.58 \pm 7.59^{\mathrm{a}}$ & $44.32 \pm 8.01^{\mathrm{a}}$ & 0.802 & 0.474
\end{tabular}

${ }^{a} \mathrm{P}<0.05$ compared with the same group and the same period prior to the operation. Tbil, total bilirubin; Dbil, direct bilirubin; ALT, alanine aminotransferase; AST, aspartate aminotransferase.

Tbil and Dbil levels after the first- and second-stage operation were higher than those prior to the first- and second-stage operation in each of the two groups, respectively $(\mathrm{P}<0.05)$. The ALT level after the first-stage operation in the two groups was also higher than that prior to the first-stage operation $(\mathrm{P}<0.05)$, and the ALT level after the second-stage operation in the two groups was significantly lower than that prior to the second-stage operation $(\mathrm{P}<0.05)$. The AST levels after the first- and second-stage operation were lower than those prior to the first- and second-stage operation, respectively $(\mathrm{P}<0.05$; Table III).

Changes in blood routine indicators in the two groups of patients. The neutrophil ratios, WBCs and hemoglobin $(\mathrm{Hb})$ concentrations were not significantly different between the two groups in all four stages of operation $(\mathrm{P}>0.05)$. The WBC count of the two groups was higher after the first-stage operation compared with that prior to the first-stage operation, but the difference was not statistically significant, which was increased further following the second-stage operation $(\mathrm{P}>0.05)$; however, the $\mathrm{WBC}$ and neutrophil counts were significantly lower after the second-stage operation compared with that prior to the second-stage operation $(\mathrm{P}<0.05$; Table IV).

Changes in coagulation function in the two groups of patients. The prothrombin time (PT), plasma fibrinogen (FIB) levels and international normalized ratio (INR) were not significantly different between the two groups in all four stages of operation examined $(\mathrm{P}>0.05)$. The PT and INR in the two groups were not significantly different between the time-points prior to and after the first- and second-stage operation $(\mathrm{P}>0.05)$, but the FIB after the first-stage operation was higher than that prior to the first-stage operation $(\mathrm{P}<0.05)$. The PT in the two groups of patients was higher after the second-stage operation than that prior to the second-stage operation $(\mathrm{P}<0.05)$, whereas the FIB level was lower $(\mathrm{P}<0.05)$ and the INR was not significantly changed $(\mathrm{P}>0.05$; Table $\mathrm{V})$.

Changes in cognitive function in the two groups of patients. Although significant declines were noted in cognitive function after first stage and after second stage operation within both control and observation groups $(\mathrm{P}<0.05)$, no differences were observed between control and observation groups at any of the four stages (Fig. 1).

\section{Discussion}

The majority of patients are newly diagnosed with liver cancer at the intermediate and advanced stages, and the use of ALPPS in the surgical treatment of liver cancer is gradually increasing (16). Effective and reasonable anesthesia is an important step to ensure the success rate and efficacy of surgery (17). Although the use of ALPPS has been increasing in surgery, only a few studies are available on the anesthesia for it. The present study aimed to explore the application 
Table IV. Changes in blood routine parameters in the two groups of patients.

\begin{tabular}{|c|c|c|c|c|}
\hline Parameter & Control group $(n=21)$ & Observation group $(n=19)$ & F-value & P-value \\
\hline \multicolumn{5}{|l|}{ Neutrophils (\%) } \\
\hline Prior to first-stage operation & $79.42 \pm 14.33$ & $81.25 \pm 14.56$ & 0.397 & 0.721 \\
\hline After first-stage operation & $81.32 \pm 15.47$ & $82.63 \pm 13.15$ & 0.144 & 0.812 \\
\hline Prior to second-stage operation & $80.48 \pm 13.24$ & $80.91 \pm 12.33$ & 0.111 & 0.943 \\
\hline After second-stage operation & $73.45 \pm 13.46^{\mathrm{a}}$ & $74.58 \pm 12.72^{\mathrm{a}}$ & 0.236 & 0.740 \\
\hline \multicolumn{5}{|l|}{$\mathrm{WBC}\left(\mathrm{x} 10^{9} / \mathrm{l}\right)$} \\
\hline Prior to first-stage operation & $10.12 \pm 1.45$ & $10.48 \pm 1.39$ & 0.901 & 0.479 \\
\hline After first-stage operation & $11.27 \pm 1.62$ & $11.73 \pm 1.48$ & 0.924 & 0.376 \\
\hline Prior to second-stage operation & $12.11 \pm 1.57$ & $12.53 \pm 1.54$ & 0.866 & 0.372 \\
\hline After second-stage operation & $9.48 \pm 1.24^{\mathrm{a}}$ & $9.87 \pm 1.26^{\mathrm{a}}$ & 0.995 & 0.357 \\
\hline \multicolumn{5}{|l|}{$\mathrm{Hb}(\mathrm{g} / \mathrm{l})$} \\
\hline Prior to first-stage operation & $122.75 \pm 18.64$ & $124.12 \pm 19.17$ & 0.221 & 0.828 \\
\hline After first-stage operation & $124.17 \pm 17.45$ & $125.32 \pm 18.69$ & 0.219 & 0.864 \\
\hline Prior to second-stage operation & $125.58 \pm 17.68$ & $123.86 \pm 18.84$ & 0.307 & 0.743 \\
\hline After second-stage operation & $123.96 \pm 18.03$ & $124.49 \pm 19.33$ & 0.024 & 0.992 \\
\hline
\end{tabular}

${ }^{\mathrm{a}} \mathrm{P}<0.05$ compared with the same group and the same period prior to the operation. WBC, white blood cells; Hb, hemoglobin.

Table V. Changes in coagulation function in the two groups of patients.

\begin{tabular}{|c|c|c|c|c|}
\hline Parameter & Control group $(n=21)$ & Observation group $(n=19)$ & F-value & P-value \\
\hline \multicolumn{5}{|l|}{ PT (sec) } \\
\hline Prior to first-stage operation & $12.17 \pm 1.35$ & $12.28 \pm 1.24$ & 0.267 & 0.791 \\
\hline After first-stage operation & $12.63 \pm 1.42$ & $12.75 \pm 1.43$ & 0.266 & 0.792 \\
\hline Prior to second-stage operation & $14.18 \pm 1.51$ & $14.29 \pm 1.53$ & 0.229 & 0.820 \\
\hline After second-stage operation & $17.52 \pm 1.64^{\mathrm{a}}$ & $17.68 \pm 1.71^{\mathrm{a}}$ & 0.302 & 0.764 \\
\hline \multicolumn{5}{|l|}{$\mathrm{FIB}(\mathrm{g} / \mathrm{l})$} \\
\hline Prior to first-stage operation & $2.63 \pm 0.12$ & $2.71 \pm 0.14$ & 1.946 & 0.059 \\
\hline After first-stage operation & $4.35 \pm 0.83^{\mathrm{a}}$ & $4.28 \pm 0.79^{\mathrm{a}}$ & 0.273 & 0.787 \\
\hline Prior to second-stage operation & $3.52 \pm 0.64$ & $3.61 \pm 0.63$ & 0.447 & 0.657 \\
\hline After second-stage operation & $2.31 \pm 0.37^{\mathrm{a}}$ & $2.28 \pm 0.36^{\mathrm{a}}$ & 0.259 & 0.797 \\
\hline \multicolumn{5}{|l|}{ INR } \\
\hline Prior to first-stage operation & $1.12 \pm 0.15$ & $1.14 \pm 0.14$ & 0.435 & 0.666 \\
\hline After first-stage operation & $1.23 \pm 0.16$ & $1.26 \pm 0.16$ & 0.592 & 0.557 \\
\hline Prior to second-stage operation & $1.42 \pm 0.18$ & $1.41 \pm 0.19$ & 0.171 & 0.865 \\
\hline After second-stage operation & $1.41 \pm 0.18$ & $1.42 \pm 0.18$ & 0.175 & 0.862 \\
\hline
\end{tabular}

${ }^{a} \mathrm{P}<0.05$ compared with the same group and the same period prior to the operation. PT, prothrombin time; FIB, plasma fibrinogen; INR, international normalized ratio.

of sevoflurane in ALPPS by retrospectively analyzing the medical records with regard to propofol and sevoflurane in patients who underwent ALPPS to provide a reference for clinical surgical anesthesia.

The present study included 40 patients with liver cancer who underwent ALPPS. No statistically significant differences between the two groups were identified regarding sex, age, operation time, operation interval and liver volume growth rate, suggesting that the data of the two groups included in the present study were comparable. The results indicated that combined sevoflurane anesthesia had no significant impact on hemodynamics compared with propofol anesthesia. No statistically significant difference in the hemodynamics indicators was identified between the two groups at any time-point examined. This is similar to the effect of propofol combined with sevoflurane anesthesia on hemodynamics in general hepatectomy. Sevoflurane has little to negligible effects on the respiratory system, does not stimulate cardiomyocytes 


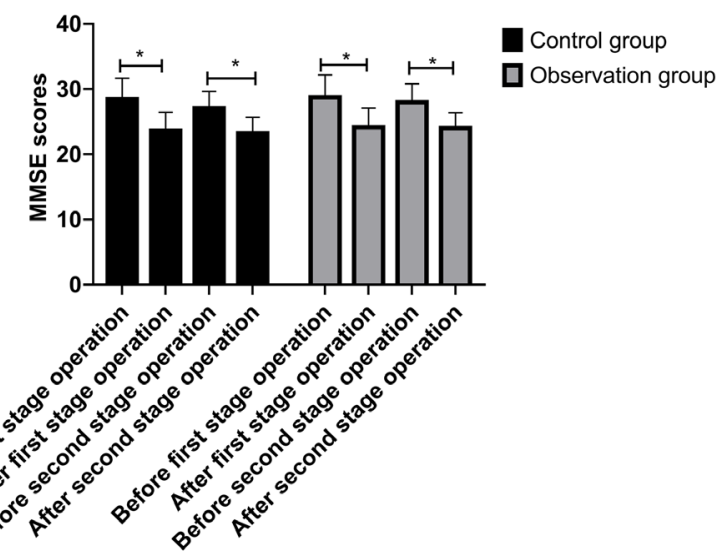

Figure 1. Changes in cognitive function in the two groups of patients. ${ }^{*} \mathrm{P}<0.05$. After the first/second stage operation, a decline in cognitive function compared with the pre-operative score was noted. MMSE, Mini Mental State Examination.

to respond to catecholamines and relieves the decline in respiratory function due to extubation, improves the blood oxygen supply capacity and stabilizes hemodynamics $(18,19)$. The study also indicated no significant changes in Hb levels in the two groups. The anesthetic drugs used in patients undergoing ALPPS should have low hepatotoxicity and low liver metabolism, should not accumulate and not increase the liver burden. The liver function analysis of the two groups of patients indicated a certain amount of damage; bilirubin accumulation occurred in the peripheral blood, and ALT and AST levels were increased after first-stage portal vein ligation. The Tbil and Dbil levels in the peripheral blood of the two groups were still elevated, but ALT and AST levels were significantly decreased after the second-stage liver resection, suggesting that the liver function of the two groups was recovering to a certain degree. The underlying reason may be that the liver was resected in the two operations and it was still unable to completely metabolize bilirubin, so the level of bilirubin was increased, while reductions in ALT and AST levels were mainly caused by hepatocyte injury, and after the treatment, the tumor is basically removed and the liver cells proliferate, so the levels of ALT and AST are decreased. However, the liver function indicators of the two groups were not significantly different between the two groups at any of the time-points regarding the first and second stage, suggesting that sevoflurane did not affect the liver function of patients. In certain liver surgeries, propofol combined with sevoflurane did not impair liver function $(20,21)$. The results of the present study indicated that the absence of any changes in leukocyte levels after the first-stage operation may be due to an increased inflammatory reaction in the body caused by the separation of bile from the portal vein ligation (22). The proportion of neutrophils also increased, which also suggested the occurrence of inflammation. After the second-stage operation, the WBC count of the two groups decreased, but the WBCs between the two groups were not significantly different after the second-stage operation, and the neutrophils also exhibited a downward trend. Anesthesia is well known to cause a decline of immune function in patients (23). This may also be a reason for the decline in WBCs after the second-stage operation. The coagulation function of the two groups of patients was then tested. Spinal anesthesia was not adopted for ALPPS, as it may affect the patients' coagulation function. The present results also revealed certain abnormalities in the coagulation function of the patients after the first- and second-stage operation. The FIB level of the two groups exhibited a significant increase after the first-stage operation, whereas the PT of the two groups increased after the second-stage operation, and statistically significant difference was obtained between the groups in the respective indicators of coagulation function. Certain studies reported that propofol and sevoflurane affect the coagulation function of patients to a certain extent, but the effect of sevoflurane on coagulation function is less than that of propofol (24-26). Therefore, propofol combined with sevoflurane anesthesia has better safety in ALPPS, but monitoring of changes in coagulation function of patients is still necessary to avoid post-operative major bleeding. Another unavoidable side effect of anesthesia is the impact on cognitive function $(27,28)$. The present results indicated a reduction in cognitive function after the first- and second-stage operation in the two groups, but propofol combined with sevoflurane did not aggravate the decrease of the cognitive function of patients, which may be due to the faster metabolism of sevoflurane. In general, one hour after stopping inhalation, the concentration of sevoflurane in the blood may be reduced to $1 / 20$ of the previous concentration, but sevoflurane also causes inhibition of synaptic function, which is one of the reasons for its effect on cognitive function (29). However, the effect of propofol combined with sevoflurane on cognitive dysfunction is generally acceptable. The present study also included a small number of cases, so the results and conclusions require verification by further studies with more clinical data. In addition, it is required to investigate the mechanism with regard to the degree of decline in cognitive function in future studies.

In conclusion, propofol combined with sevoflurane has a good application value in ALPPS, as addition of sevoflurane has little effect on the hemodynamic stability of patients and improves the level of inflammatory response, but does not increase the effects on liver function, coagulation and cognitive function.

\section{Acknowledgements}

Not applicable.

\section{Funding}

No funding was received.

\section{Availability of data and materials}

All data generated or analyzed during this study are included in this published article.

\section{Authors' contributions}

FX and QHP conceived the study and designed the experiments. HBJ and MSJ contributed to the data collection, performed the data analysis and interpreted the results. FX wrote the manuscript and QHP contributed to the critical 
revision of the article. All authors read and approved the final manuscript.

\section{Ethics approval and consent to participate}

The study was approved by the hospital ethics committee of The Jilin Hepatobiliary Hospital (Jilin, China), and the patients or a family member provided written informed consent.

\section{Consent for publication}

Not applicable.

\section{Competing interests}

All authors declare that they have no competing interests.

\section{References}

1. Kudo M, Matsui O, Izumi N, Iijima H, Kadoya M, Imai Y, Okusaka T, Miyayama S, Tsuchiya K, Ueshima K, et al: JSH consensus-based clinical practice guidelines for the management of hepatocellular carcinoma: 2014 update by the Liver Cancer Study Group of Japan. Liver Cancer 3: 458-468, 2014.

2. Kudo M: Surveillance, diagnosis, treatment, and outcome of liver cancer in Japan. Liver Cancer 4: 39-50, 2015.

3. Oishi N, Yamashita T and Kaneko S: Molecular biology of liver cancer stem cells. Liver Cancer 3: 71-84, 2014.

4. Ryerson AB, Eheman CR, Altekruse SF, Ward JW, Jemal A, Sherman RL, Henley SJ, Holtzman D, Lake A, Noone AM, et al: Annual report to the nation on the status of cancer, 1975-2012, featuring the increasing incidence of liver cancer. Cancer 122: 1312-1337, 2016.

5. Baltatzis M, Chan AK, Jegatheeswaran S, Mason J and Siriwardena A: Colorectal cancer with synchronous hepatic metastases: Systematic review of reports comparing synchronous surgery with sequential bowel-first or liver-first approaches. Eur J Surg Oncol 42: 159-165, 2016.

6. Silberhumer GR, Paty PB, Denton B, Guillem J, Gonen M, Araujo RL, Nash GM, Temple LK, Allen PJ, DeMatteo RP, et al: Long-term oncologic outcomes for simultaneous resection of synchronous metastatic liver and primary colorectal cancer. Surgery 160: 67-73, 2016

7. Leung U, Gönen M, Allen PJ, Kingham TP, DeMatteo RP, Jarnagin WR and D'Angelica MI: Colorectal cancer liver metastases and concurrent extrahepatic disease treated with resection. Ann Surg 265: 158-165, 2017.

8. Petrowsky H, Györi G, de Oliveira M, Lesurtel M and Clavien PA: Is partial-ALPPS safer than ALPPS? A single-center experience. Ann Surg 261: e90-e92, 2015.

9. Lang H, de Santibanes E and Clavien PA: Outcome of ALPPS for perihilar cholangiocarcinoma: Case-control analysis including the first series from the international ALPPS registry. HPB (Oxford) 19: 379-380, 2017.

10. Olthof PB, van Gulik TM and Bennink RJ: The Hiba index for Alpps, preliminary results to interpret with caution. Ann Surg 267: e97-e98, 2018.

11. Schadde E, Ardiles V, Robles-Campos R, Malago M,Machado M, Hernandez-Alejandro R, Soubrane O, Schnitzbauer AA, Raptis D, Tschuor C, et al: Early survival and safety of ALPPS: First report of the International ALPPS registry. Ann Surg 260: 829-838, 2014

12. Pan X, Zhao B, Xiao Y,Hou J and Xia Z: Effects of different duration of sevoflurane anesthesia in neonatal period on long-term cognitive func-tion and hippocampal synaptic plasticity in rats. Chin J Anesthesiol 36: 1085-1088, 2016.
13. Nadalin S, Capobianco I, Li J, Girotti P, Königsrainer I and Königsrainer A: Indications and limits for associating liver partition and portal vein ligation for staged hepatectomy (ALPPS). Lessons learned from 15 cases at a single centre. Z Gastroenterol 52: 35-42, 2014.

14. Trzepacz PT, Hochstetler H, Wang S, Walker B and Saykin AJ; Alzheimer's disease neuroimaging initiative: Relationship between the montreal cognitive assessment and mini-mental state examination for assessment of mild cognitive impairment in older adults. BMC Geriatr 15: 107, 2015.

15. De Valence T, Elia N, Czarnetzki C, Dumont L, Tramèr MR and Lysakowski C: Effect of sufentanil on bispectral index in the elderly. Anaesthesia 73: 216-222, 2018.

16. Xiao L, Li JW and Zheng SG: Totally laparoscopic ALPPS in the treatment of cirrhotic hepatocellular carcinoma. Surg Endosc 29: 2800-2801, 2015.

17. Jiang Y, Chen Y, Xin L and Shuchang X: Factors influencing the detection rates of colonoscopic polyp and adenoma in high-risk population in colorectal cancer screening. Chin J Digestive Endoscopy 32: 649-652, 2015.

18. Mathur V, Garg D, Jain N, Singhal V, Khare A and Sethi SK: A comparative study of propofol and $\mathrm{N} 2 \mathrm{O}$ versus sevoflurane and $\mathrm{N} 2 \mathrm{O}$ with respect to haemodynamic response and ease of laryngeal mask airway insertion: A prospective randomized double blinded study. Int J Res Med Sci 4: 3421-3426, 2017.

19. Khare A, Mathur V, Jain K, Sethi SK, Garg D and Vishnoi R: A prospective randomized study for comparison of haemodynamic changes and recovery characteristics with propofol and sevoflurane anaesthesia during laparoscopic cholecystectomies. Int J Res Med Sci 4: 5241-5247, 2016.

20. Xu Z, Yu J, Wu J, Qi F, Wang H, Wang Z and Wang Z: The effects of two anesthetics, propofol and sevoflurane, on liver ischemia/reperfusion injury. Cell Physiol Biochem 38: 1631-1642, 2016.

21. Yamada T, Nagata H, Kosugi S, Suzuki T, Morisaki H and Kotake Y: Interaction between anesthetic conditioning and ischemic preconditioning on metabolic function after hepatic ischemia-reperfusion in rabbits. J Anesth 32: 599-607, 2018.

22. Neal C, Cairns V, Jones M, Garcea G and Dennison AR: Comparison of the prognostic value of systemic inflammatory indices in patients with resectable colorectal liver metastases. HPB 18: e722-e723, 2016.

23. Zhuo J, Liu C and Yin G: Effects of dexmedetomidine on the perioperative stress response and immunologic function in hepatectomy patients with hepatitis cirrhosis. J Clin Anesthesiol 32: 645-649, 2016.

24. Shoreem H, Ayoub I, Lasheen H, Hegazy O, Lotfy M, Saleh S, Yassein T, Sallam A, Aziz A, Ibrahim T and Abou El-Ella K: Improved outcome of emergent management of incarcerated Para-umbilical hernia in patients with decompensated cirrhosis under local anesthesia and weak sedation: A prospective randomized comparative study. HPB 18: e79-e80, 2016.

25. Bu X, Wang B, Wang Y, Wang Z, Gong C, Qi F and Zhang C: Pathway-related modules involved in the application of sevoflurane or propofol in off-pump coronary artery bypass graft surgery. Exp Ther Med 14: 97-106, 2017.

26. Zhang LJ, Lv JP and Wang XY: A comparison of the effect of propofol versus sevoflurane on blood coagulation functions of patients undergoing retroperitoneal laparoscopy. J Clin Anesthesiol 2: 003, 2015.

27. Cen S, Haiqing F and Liang L: Comparison of sevoflurane and propofol on cerebral oxygen metabolism and postoperative cognitive function during anesthesia maintenance. Chin J Biochemical Pharmaceutics 37: 177-182, 2017.

28. Yang S, Gu C, Mandeville ET, Dong Y, Esposito E, Zhang Y, Yang G, Shen Y, Fu X, Lo EH and Xie Z: Anesthesia and surgery impair blood-brain barrier and cognitive function in mice. Front Immunol 8: 902, 2017.

29. Sorour K, Vyas P, Raval D, Donovan L and Vyas A: Successful treatment of severe asthma exacerbation with sevoflurane inhalation in the intensive care unit. J Anesth Crit Care Open Access 3: 00092, 2015. 